\title{
Odredbe istarskih statuta u svezi s poštivanjem Božjih i crkvenih zapovijedi ${ }^{1}$
}

\author{
Prethodno priopćenje \\ Preliminary communication
}

UDK 352.07(497.5-3 Istra):241.6>:395

\begin{abstract}
Jedna od glavnih odrednica u statutima istarskih gradova i općina svakako je odnos pojedinca prema Bogu, vjeri i vjerskoj praksi. Svi oni tretiraju pitanje psovke, rada nedjeljom i zapovijedanim blagdanima. Neki kaznene propise u svezi s psovkom donose na početku, neki u kasnijim odredbama, ali su u svakom slučaju kazne vrlo stroge, a ponekad i drastične. Vrlo su stroge odredbe o radu nedjeljom i zapovijedanim blagdanom, kao i radom krčmi nedjeljom i blagdanom prije završetka župne mise. Autor na početku rada donosi popis sačuvanih statuta nastalih na području Istre, najprije na području hrvatskog dijela za koji je nadležan Državni arhiv u Pazinu, a zatim i na današnji slovenski i talijanski dio. Ograničio se na manji broj statuta.
\end{abstract}

Ključne riječi: statut, psovka, nedjelje i blagdani, kazna, globa, izgon, galija

\section{Kratki uvod}

$\mathrm{N}$ ašoj i svjetskoj znanstvenoj javnosti nije nepoznato da je područje Istre pravi Eldorado sačuvanih komunalnih statuta. Gotovo svi su objavljeni, a u posljednje vrijeme sačinjen je projekt Kolana od statuti, kojem je cilj ponovno objaviti sve statute nastale na području današnje Istarske županije u izvornom tekstu te njihov prijevod s potrebnim znanstvenim aparatom, a za svaki statut predviđen je povijesni i pravni uvod.

Ovi se statuti uglavnom čuvaju u Državnom arhivu u Pazinu (DAPA), a dio se prijepisa nalazi u Državnom arhivu u Rijeci (DARI) te u Veneciji i Trstu. Jedini sačuvani primjerak prijepisa Vrsarskog statuta čuva se u Biskupijskom arhivu u Poreču.

Dr. Danilo Klen u Uvodnim napomenama svog rada pod naslovom Statut Grožnjana navodi istarska mjesta koja su prema Carlu Combiju u Saggio di bibliografia istriana (Kopar, 1864.) i Ivanu Strohalu "Statuti primorskih gradova i općina“ (Zagreb, 1911.) imala statute. Mjesta su navedena abecednim redom. Navode se statuti s područja Hrvatske i današnje Slovenije. Dio statuta s područja Hrvatske pripada području što ga pokriva Državni arhiv u Pazinu (područje Istarske županije), a dio pripada području što ga pokriva Državni arhiv u Rijeci. U popisu je navedena i Muggia (kao Milje), koja pripada Italiji (Klen 1963-1964: 207).

1 Ovaj je rad proširena verzija priopćenja održanog 2008. na Kongresu povjesničara u Supetru na otoku Braču pod naslovom Odredbe istarskih statuta u svezi s vjerskom praksom (dodani su propisi u svezi s psovkom na Boga i svece).

Zahvaljujem kolegici profesorici Maji Cerić, arhivistici u DAPA. 
U popisu se navode sljedeća mjesta:
1. Bale
14. Mošćenice
2. Barban
15. Motovun
3. Boljun
16. Novigrad
4. Buje
17. Oprtalj
5. Buzet
18. Piran
6. Dvigrad (Dvigrađe) ${ }^{2}$
19. Plomin
7. Grožnjan
20. Poreč
8. Izola (Izula)
21. Pula
9. Kastav
22. Rovinj
10. Kopar (Koper)
23. Umag
11. Labin
24. Veprinac
12. Lovreč
25. Vodnjan
13. Muggia (Milje)
26. Vrsar

Klen u svom radu navodi da se „danas" smatraju zagubljenima statuti Boljuna, Lovreča, Plomina i Vrsara (Klen 1963-1964: 207).

Klen navodi da je u Popisu naveo i Barban, koji navode i Combi i Strohal, premda je jasno da se ne radi o statutu, te da je unio i Plomin koji navedeni autori ne navode, a učinio je to prema kazivanju prof. Branka Fučića (Klen 1963-1964: 207).

Fučićeva se tvrdnja pokazala ispravnom. Statut je doista većim dijelom zagubljen, a Bernard Stulli je sačuvani fragment ovog statuta objavio u Vjesniku. ${ }^{3}$

Imao sam veliku sreću da sam najprije 1971. godine pronašao kopiju statuta Svetog Lovreča Pazenatičkog, i to u Kopru kod jednog privatnika i objavio ga (Jelinčić 1973: 18), a 2002. u Biskupijskom arhivu u Poreču Statut Vrsara.

$\mathrm{Na}$ taj se način broj zagubljenih statuta sveo na onaj boljunski, no osobno ne vjerujem da je on ikada i postojao. Naime, osim u navedenim popisima nisam nigdje našao da se $u$ literaturi spominje.

Treba reći da je, prema nekim izvorima postojao i statut Svetvinčenta.

U Državnom arhivu u Pazinu (DAPA) čuvaju se izvornici ili prijepisi sljedećih statuta:

Bala, Buja (fragment), Buzeta, Dvigrada, Grožnjana, Novigrada, Plomina (fragment), Poreča, Pule, Rovinja, Svetog Lovreča Pazenatičkog i Vodnjana.

Gotovo svi istarski statuti, uz ostale propise, donose i stroge propise o psovkama, propisujući razne fizičke kazne ili novčanu globu, a u slučaju nemogućnosti njenog plaćanja, također razne fizičke kazne. Donose također propise o vjerskoj praksi u smislu poštivanja nedjeljnog i blagdanskog odmora te propisuju globu ukoliko se u tim danima rade fizički poslovi (opera servilia). Donose i propise u svezi sa sudovanjem u tim danima.

$\mathrm{U}$ ovom se radu osvrćem na jedan i na drugi segment.

\section{Psovka}

Kazne predviđene za psovku su različite, ali u pravilu vrlo stroge. Neki statuti je tretiraju u prvoj glavi prve knjige (ukoliko je statut podijeljen na knjige), a neki u četvrtoj.

U zagradama navodim oblike koje u svom radu navodi D. Klen.

Bernard Stulli, „Fragment Statuta Plominske općine“, Vjesnik historijskih arhiva u Rijeci i Pazinu (VHARIP), sv. 14, Rijeka 1969., 7-49. 
U prvoj glavi prve knjige nalazimo je npr. u grožnjanskom i vodnjanskom statutu. Vrsarski statut podijeljen je u dvije knjige. Prva knjiga uređuje građanska pitanja, a druga kaznene predmete. $U$ potonjoj se propis protiv psovke donosi u prvoj glavi.

Pri navođenju prijevoda nekih glava držim se objavljenog teksta, uz napomenu da su prijevodi šaroliki, s obzirom na terminologiju pravnih instituta (npr. tužitelj, prijavitelj, dojavnik i sl. za istu funkciju).

Najsvečanijim mi se čini uvod u prvu glavu prve knjige u grožnjanskom Statutu, jer u zabrani navodi Mojsija na brdu Sinaju i spominjanje Gospodnjeg imena uzalud.

Zbog ograničene dužine priloga donosim samo prijevod:

\section{Da se nitko ne usudi psovati Boga i svece}

Budući da je Bog Božanskim zakonom naredio proroku Mojsiju na Brdu Sinaju da treba prije svega častiti samo jednog Boga i da se njegovo uzvišeno ime ne smije izgovarati uzalud, mi dakle, hoteći svim snagama obdržavati toliku Božju zapovijed, da stvorenje uzvratnim dobrom odgovori Stvoritelju, ovom odredbom strogo naređujemo da se bilo koji naš doseljenik i stanovnik ne usudi psovati svemogućega Boga, njegovu Blaženu Djevicu i Majku Mariju i svece i svetice na bilo koji način koji se može zamisliti. Oni koji to krše, psujući svemogućega Boga i Njegovu Majku trebaju biti kažnjeni globom od 25 lira za svaki put, a ako opsuje svece i svetice 10 lira za svaki put, od kojih neka bez mogućnosti oprosta jedna trećina pripadne našem uzvišenom načelniku, druga trećina zajednici, odnosno općini Grožnjan, a ostalo dojavniku. Ukoliko pak ne bi htio ili ne bi mogao platiti neka pola dana stoji uz stup srama za primjer drugima. ${ }^{4}$

Kazna je utoliko posebna u odnosu na druge statute da se, što je i logično, oštrije sankcionira psovka na Boga i Blaženu Djevicu Mariju u odnosu na onu na svece i svetice Božje: u prvom slučaju 25 lira, a u drugom 10 lira. U slučaju nemogućnosti plaćanja predviđa se kazna od pola dana stajanja uz stup srama.

Novigradski statut psovku tretira u 1. glavi 6. knjige. Novčana je globa 20 solada, ali se u nemogućnosti plaćanja počinitelj kažnjava s osam dana zatvora. Donosim samo talijanski tekst:

\section{Della Blastema dita a Cristo, e alla Mare e altri Santi Capitolo. I.}

Comandemo che ziascadun, che Blastemera, over dira altra inzuria al nostro Signor Jesucristo, over alla Gloriosa Verzene Maria soa Mare, subito paga in comun soldi vinti zenza alguna indusia. Se veramente a altri Sancti (!) soldi diese, li qual sel no pagara, diebbia star otto dì in presion. ${ }^{5}$

Kazne u buzetskom i oprtaljskom statutu su jednake: oba statuta predviđaju da u nemogućnosti plaćanja globe od deset lira malih denara psovač bude triput bačen u jezero (buzetsko odnosno oprtaljsko) u odjeći koju u tom trenutku bude imao na sebi.

Navodim odredbu buzetskog statuta samo na hrvatskom jeziku:

Prijevod: J. Jelinčić.

Statut Novigrada priređen je za tisak (transkripcija, uvod i jezična obrada J. Jelinčić, povijesna studija Miroslav Bertoša, pravna studija i prijevod Nella Lonza, kazala J. Jelinčić i Nella Lonza). 
Glava X.

O onima koji hule Boga i svece.

Ako netko ubuduće pohuli ili opsuje Boga, njegovu slavnu majku ili druge svece, neka plati općini kaznu od deset malih libara, a ako ne bude mogao to platiti, treba ga sa svom odjećom na njemu triput baciti u jezero svetog Ivana, a svatko može da tuži ili prijavi takve hulitelje i neka se drži u tajnosti te neka mu se vjeruje i samo s jednim svjedokom, tako da je potreban tom tužitelju ili prijavitelju samo jedan svjedok, da bi dokazao svoju tužbu ili prijavu, od koje kazne polovica neka pripadne mletačkoj i buzetskoj općini, a druga polovica tužitelju ili prijavitelju (Zjačić 1964-1965: 152).

Vrsarski statut u drugoj knjizi, koja govori o kaznenim djelima, posvećuje pitanjima psovke i drugih svetogrdnih djela ček tri prve glave, a četvrtu posvećuje kultu.

Ovo je očekivano jer kazne propisuje biskup.

Prva je glava drakonski stroga, jer predviđa bušenje jezika ili veslanje na galiji prema biskupovoj prosudbi.

Stroga je kazna i za udaranje svete slike ili nedoličan čin prema njoj, za što je predviđena kazna odsijecanje ruke kojom je počinjeno nedjelo.

\section{Della biastema.}

Rubrica 1.

Essendo il delitto della biastema un'offesa immediatamente diretta contro la Maestà di Dio, e Noi perciò volendo come è giusto e conveniente prima d'ogn'altra cosa con opportuno rimedio provedere che tale essecrabil vitio non abbi sede ne luoco in qualsivoglia tempo per l'avenire in questo Nostro Contado,

Statuemo, che chiunque di che stato, grado e conditione si sia con qualsivoglia biastema ardirà biastemare il Nome di Dio o della Beata Vergine per la prima volta incora in pena di trè tratti di corda, e per la seconda oltre la sudetta pena incorra in pena di scudi 50:, et per la terza volta s'intenda incorso in pena della perforatione della lingua, o vero della galera ad arbitrio Nostro. ${ }^{6}$

\section{O psovci \\ Glava 1.}

Budući da je zločin psovke neposredna (i) izravna uvreda protiv Božjeg Veličanstva, i Mi stoga hoteći kako je pravedno i prikladno prije svega da ta užasna mana ne bude prisutna u bilo kojem vremenu u budućnosti u ovoj Našoj Grofoviji, određujemo da ukoliko se tko bilo kojeg staleža, stanja i položaja usudi opsovati Ime Boga ili Blažene Djevice prvi put neka potpadne pod kaznu od tri trzaja na koloturi, za drugi put, osim navedene kazne neka

\footnotetext{
Statuti et ordini da osservarsi nel Castello d'Orsera et Contado ordinati dall'illustrissimo e reverendissimo vescovo di Parenzo, cioe Signor di detto Luoco Monsignor Leonardo Tritonio, I'anno MDCVIIII. Čuva se u Biskupijskom arhivu u Poreču. (str. 120).

Napomena: Ovaj se naslov odnosi na prvi Statut. Novi Statut donesen je (za sada) neutvrđene godine (čini se u XVIII. st.).

Novi je Statut donesen kako bi se propisi postrožili. Međutim, u starome Statutu ova je odredba bila stroža: rezanje jezika (d'esserle tagliata la lingua), tri mjeseca zatvora (star tre mesi in prigione serata) i dvije godine izgona iz Vrsara i njegova teritorija (due anni de bando da questo Castello et territorio) bez nade o pomilovanju (senza speranza d'ottenere grazia alcuna) (str. 1).
} 
upadne u kaznu od 50 škuda, a za treći put neka se smatra da je upao u kaznu bušenja jezika ili (veslanja na) galiji prema Našem nahođenju. ${ }^{7}$

Della percussione dell'imagini di Dio, o della Beata. Vergine, o de Santi, et attioni indicenti verso di quelle.

\section{Rubrica 2.}

Se alcuno sara di tanta audatia, e da cosi diabolico spirito indotto, che ardisca percuotere, imbratare o deformare alcuna immagine di Dio, o vero della Beata Vergine o Croce in qualsivoglia luoco posta, o vero farà qualche gesto o attione indegna et indecente verso alcuna di esse, o contro l'imagine de Santi, ordiniamo che li sia troncata la mano chi li sarà stato empio instrumento a comettere il temerario ecesso, oltre l'esser perciò condannato ancora in pena a Noi arbitraria. ${ }^{8}$

O udaranju na sliku Božju ili Blažene Djevice, ili svetaca, i nedoličnih čina protiv njih.

Glava 2.

Ako netko bude toliko drzak i tako zaveden vražjim duhom da bi se usudio udariti, zamrljati ili izobličiti neku sliku Božju ili Blažene Djevice ili križ postavljene na bilo kojem mjestu, ili učini bilo kakvu nedostojnu ili nedoličnu gestu prema nekoj od njih ili protiv slikâ svetaca, određujemo da mu se odsiječe ruka koja mu je bila sredstvo za izvršenje drskog djela, osim što će biti od nas osuđen na kaznu prema Našem nahođenju.

Che nelli delitti sudetti, biastema, attioni indecenti ciascuno sia tenuto denunciare.

Rubrica 3.

Per rimovere afatto ogni adito al potere, ne anco ardire di pensare all'occasioni, nonche al comettere alcuno delli sopradetti delitti, statuemo et ordiniamo che qualunque (eccetuando il padre et il figliuolo vicendevolmente) il quale si trovarà presente ad alcuno di questi essecrandi delitti, sia tenuto in termine d'un giorno denonciarlo alla Nostra cancellaria, sotto pena di scudi 25: o vero di trè tratti di corda ad arbitrio. ${ }^{9}$

Da je u rečenim zločinima, psovki (i) nedoličnim činima svatko dužan prijaviti.

Glava 3.

Da bi se svakoga odvratilo od toga da može i usudi se razmišljati o prilikama ${ }^{10}$, a nekmoli o izvršenju nekog od navedenih zlodjela, određujemo i naređujemo da je bilo tko (osim oca i sina i obrnuto) tko bude nazočan ovim gnusnim zlodjelima, dužan u roku jednog dana prijaviti ga u Našu kancelariju pod prijetnjom globe od 25 škuda ili tri trzaja na koloturi po (Našem) nahođenju.

Glave vrsarskog Statuta preveo J. Jelinčić.

Konac 120. i početak 121. stranice.

Str. 121.

10 Tekst je djelomično nejasan pa tako i prijevod djelomično nesiguran. Vjerojatno je pri prijepisu iz zagubljenog izvornika došlo do pogreške. 


\section{Di quelli bestemiaranno Dio over li santi Capitolo I}

Ordinemo, che s'alcuna persona da qui indietro bestemiarà, overo vituperarà l'Omnipotente Iddio et la sua gloriosa Vergine Maria, paghi lire dieci dè picoli et se il bestemiarà l'evangelista prottetor nostro San Marco, lire cinque de picoli et s'il bestemiarà, overo vituperarà alcun altro santo, over santa di Dio, paghi lire tre de picoli per cadaun contrafacciente et per cadauna volta, le qual pene siano applicate al Commun di Venetia ${ }^{11}$ et all'accusator, per il qual s'haverà la verità per metà, et se non havesse onde pagar, debbia star per un giorno in berlina et cadauno possi accusar, et l'accusator sii tenuto secreto (Lonza et al. 2010: 474 i 475).

Motovunski statut tretira psovku u 60. glavi (Morteani 1895: 263).

Pulski statut nema posebnu glavu o psovci. Propis u svezi s psovanjem nalazi se u odredbi prve glave IV. knj., čiji naslov glasi De poenis dicentis verba iniuriosa (Kazna za vrijeđanje riječima). Slične naslove imaju i drugi istarski statuti, ali, koliko je meni poznato, za psovku svi, osim umaškog Statuta imaju posebnu glavu. Odredba glasi:

Item quod, si quis blasfemaverit vel iniuriam aliquam aut contumeliam dixerit contra Deum Christum seu Matrem Suam Virginem Mariam, aut aliquos sanctos eius, solvat Communi soldos centum parvorum; de quibus centum soldis deveniat acusator soldis viginti parvorum ea die qua fuerit accusatus, et si dicti accusati non solverint dicta die, demergatur in aqua portus Polae, et quilibet audiens possit accusare (Križman 2000: 157).

Isto tako, pohuli li tkogod, ili uvredu ili pak pogrdu izrekne protiv Krista Boga i Njegove Matere Blažene Djevice Marije, ili kakva sveca Njegova, neka plati Općini stotinu soldâ malog novca; od tih stotinu soldâ neka dojavniku dopadne 20 soldâ na dan kada onaj bude optužen; a ako rečeni optuženici ne budu platili rečenoga dana, valja ih utopiti u moru pulske luke; i neka je svakomu tko čuje slobodno podići tužbu.

U svezi s ovim prijevodom potrebno je pojasniti sljedeće: latinski glagol demergere ima značenje potopiti, zagnjuriti, uroniti (Marević 2000: 708), nikako utopiti (submergere). To, uostalom, proizlazi također iz primarne i subsidijarne kazne u istoj glavi. ${ }^{12}$

\section{Neradni dani}

Neki statuti taksativno nabrajaju zapovijedane blagdane u kojima se, pod prijetnjom globe, ne smiju raditi fizički poslovi, a neki samo navode da se tih dana ne smije raditi, očito pretpostavljajući da će ljudi redovito ići na nedjeljnu misu i od župnika čuti obavijest o blagdanu u narednom tjednu.

U svim su komunama, osim nedjelja, zajednički blagdani Božić, Uskrs, Gospini i drugi od Crkve propisani blagdani (blagdani apostolâ, mučenikâ i drugih svetaca), a u nekim se statutima navode i drugi blagdani, koji se slave samo na području pojedine komune, pa tako u Novigradu nalazimo 39 blagdana, u Dvigradu 50, a u Puli čak 68.

11 Odredbu da se polovica globe daje Veneciji, a polovica općini (dio ide dojavniku) nalazimo u buzetskom (gl. 1), Mirko Zjačić, „Statut buzetske općine iz 1435. godine“, str. 106.; oprtaljskom (gl. 1), Giovanni Vesnaver, Notizie storiche del Castello di Portole nell'Istra, III. dio: Statuto municipale di Portole, str. 134/135.

Istu odredbu nalazimo u Vodnjanskom statutu u nekoliko glava, kao npr. u 36. glavi III. knjige 1. glavi IV. knjige.

12 U glavi 10. buzetskog statuta koja predviđa istu kaznu (ondje: bacanje u jezero) stoji glagol proicere (baciti van, baciti preda se, aliquem praecipitem in undas proicere - strmoglaviti koga u more) (Marević, sv. 2, 2495). 
Zanimljiv je slučaj Novigrada. Novigradski statut, nabrajajući u glavi 10. Druge knjige 39 blagdana u kojima se ne radi, ne spominje blagdan mjesnog zaštitnika sv. Pelagija. No, iste godine, 1401. kada je Statut donesen, za vrijeme novigradskog podestata Francesca Premarina, donesen je na sjednici Vijeća Komune zaključak u svezi s tim blagdanom. Tog je, naime, dana, kao i dan prije i dan nakon njega, svatko, bilo građanin Novigrada, bilo stranac, smio doći u Novigrad i prodavati vino, bez plaćanja daće, ako je i bio radi nečeg optužen. Od tog su oprosta bili izuzeti oni kojima je zbog zlodjela bila predviđena tjelesna kazna (primjerice izdajice i razbojnici). Ova je odredba bila donesena samo za 1401. godinu, a za budućnost, neka bude trajna ukoliko se bude vidjelo da je na korist građanima. U protivnom neka odluku donese rektor preko Vijeća ili kancelara. Također se određuje da tih triju dana svatko smije prodavati meso uz obvezu plaćanja daća daćaru klaonice.

Novigradski statut osim šest osnovnih glava ima dvije dodane (aggiunte). Ova je odredba kasnije unesena u Statut kao 37. glava sedme knjige. ${ }^{13}$

Vrsarski statut ovako tretira rad nedjeljom i zapovijedanim blagdanom:

\section{Dell'osservanza delle feste.}

Rubrica 4:

Quelli i quali nelli giorni festivi di precetto dalla Santa Chiesa lavorarano, non havendo licenza in scriptis da Noi o dal reverendo pievano di questo luoco, quando occoresse lavorare per qualche necessità urgente incorerano in pena de scudi dieci per cadauno et per cadauna volta d'applicarsi un terzo all'accusatore et il resto alli luoghi pii. ${ }^{14}$

O poštivanju blagdanâ

Glava 4.

Oni koji budu radili u dane zapovijedanih blagdana Svete Crkve, nemajući Naše pismeno odobrenje ili od velečasnog župnika ovog mjesta, kada bi se moralo raditi zbog neke hitne potrebe, neka potpadnu pod globu od deset škuda za svakog i za svaki put od koje će se trećinu dati tužitelju, a ostalo nabožnim ustanovama. ${ }^{15}$

U dvigradskom i grožnjanskom statutu nalazimo neke posebnosti u obdržavanju zabrane sudovanja.

U dvigradskom, osim Božića i Uskrsa, glavnih godišnjih blagdana, uz koje je određena zabrana sudovanja po 15 dana prije i nakon njih, ovdje nalazimo jednaku zabranu i za blagdane sv. Petra u lipnju te sv. Mihovila u mjesecu rujnu (gl. 133.):

\section{Capitulum CXXXIII.}

De feriis et de laborantibus in eis.

Et ordinamus super feriis obtinendis, quod per dies quindecim ante festum Nativitatis Dominice et totidem post, et per dies quindecim ante festum Resurectionis Dominice et totidem post, et per dies quindecim ante festum beati Petri appostoli, de mense lunii, et per totidem post, et per dies quindecim ante festum sancti Michaelis de mense Septembris, et per totidem post, et festum sancte Marie, sancti Blasii et sancti Matie appostoli de mense Februarii, festum sancte Marie de mense Martii, festa sanctorum Marci evengeliste et

Tekst novigradskog Statuta, koji je spreman za objavljivanje sadrži šest knjiga. Sedma i osma su kasnije dodane. Konac 121. i početak 122. stranice.

Prijevod J. Jelinčić. 
Gregorii de mense Aprilis, festa sanctorum lacobi et Philippi, Victoris et Corone, sancte Crucis, Assumptionis Dominice et sancte Petronille de mense Maii; item festa sanctorum Barnabe appostoli, loannis Baptiste, Petri et Pauli et Corporis Christi de mense lunii; festa sancte Marie Mandalene (!), sanctorum lacobi et Christofori de mense Iulii; item festa sanctorum Salvatoris et Sisti, Vincula sancti Petri, Felicite, Laurentii, Assumptionis beate Marie Virginis, Bartolomei appostoli, Deccollatio sancti loannis Baptiste de mense Agusti (!), item festa beate Marie Virginis, sanctorum Mathei appostoli, Michaelis, Sophie et Eufemie de mense Septembris; item festa sanctorum Luce evageliste et Simonis [et] lude appostolorum de mense Octobris; item festa Omnium Sanctorum, Martini, Mauri et Andree appostoli de mense Novembris; item festa sancte Lucie, sanctorum Nicolai, Thome appostoli, Nativitatis Dominice, Stephani martiris et loannis evangeliste de mense Decembris et Circumcisionis Dominice et Epiphanie et sancti Antonii der mense lanuarii et festum Pentecostes cum duobus sequentibus festis sanctorum Stefani et lohannis pro feriis habeantur et teneantur, et ferie sint. In quibus regimen non debeat sedere pro tribunali pro iure redendo neque ius reddere debeat in dictis feriis, nisi in casibus in aliis nostris statutis specificatis.

\section{Glava CXXXIII.}

O blagdanima i onima koji na te dane rade. (Lonza et al: II, 27, 105)

Glede blagdana određujemo da se trebaju obdržavati ovi: petnaest dana prije svetkovine Rođenja Gospodnjeg, i toliko nakon toga, petnaest dana prije svetkovine Uskrsnuća Gospodnjeg, i toliko nakon, petnaest dana prije svetkovine blaženoga Petra apostola u lipnju i toliko nakon nje, i petnaest dana prije svetkovine svetog Mihovila u rujnu i toliko nakon nje, i blagdani svete Marije, svetog Blaža, i svetog Matije apostola u veljači, svetkovina svete Marije u ožujku, blagdani svetih Marka evanđelista i Jurja u travnju, blagdani svetih Jakova i Filipa, Viktora i Korone, svetoga Križa, Uzašašća Gospodnjega i svete Petronile u svibnju, također blagdani svetih Barnabe apostola, Ivana Krstitelja, Petra i Pavla, Tijelova u lipnju, blagdani svete Marije Magdalene, svetih Jakova i Kristofora u srpnju, također blagdani svetih Salvatora i Siksta, svetog Petra u okovima, Felicite, Lovre, Uznesenja blažene Djevice Marije, Bartola apostola, Glavosijeka svetog Ivana Krstitelja u kolovozu, također blagdani blažene Djevice Marije, svetih Mateja apostola, Mihovila, Sofije i Eufemije u rujnu, također blagdani svetog Luke evanđeliste i Šimuna i Jude, apostolâ u listopadu, blagdani Svih Svetih, svetih Martina, Mavra, i Andrije apostola u studenom, isto tako blagdan svete Lucije, svetih Nikole, Tome Apostola, Rođenja Gospodnjeg, Stjepana mučenika i Ivana evanđelista u prosincu, i Obrezanja Gospodnjeg i Bogojavljenja i svetog Antuna u siječnju, i blagdan Duhova, s dva dana koja slijede blagdane svetih Stjepana i Ivana. Navedeni dani neka se smatraju blagdanima i neka se kao takvi drže i budu. $U$ te dane uprava ne smije zasjedati kao sud, niti u navedenim blagdanima smije suditi, osim u slučajevima posebno navedenima u drugim našim statutarnim odredbama. (Jelinčić et al. 2007: 272).

U grožnjanskom se Statutu također zabrana odnosi na iste blagdane, ali je ograničenje dvostruko kraće: po osam dana prije i poslije blagdana (knj. I., gl. 14) (Klen 1963-1964: 219/220).

Kao primjer statuta koji ne navode blagdane, navodim ovdje buzetski, oprtaljski i svetlovrečki. Ipak, ovaj potonji je u tom pitanju specifičan.

Premda u njemu nema poglavlja o blagdanima, u glavi 31. Četvrte knjige govori se o giorni festivi per precetto divino e cattolico. Drugim riječima, razlikuju se blagdani po Božjoj zapovjedi (nedjelje) i po crkvenoj zapovjedi (crkveni blagdani). Budući da potonji nisu naznačeni u Statutu, navodi se da će iste oglašavati svećenici na misama (festa di precetto da sacerdoti nella chiesa ne giorno di domenica) (Jelinčić 1973: 143). 
Treba ipak reći da se u svim statutima navode iznimke te se dozvoljava sudovanje u svezi s oružjem, konjima, životinjama, zbog obveze davanja hrane i pića, kao i zbog plaćanja nadnice.

Tako se npr. u glavi 121 . buzetskog Statuta navodi da se u blagdanske dane može sudovati u svezi s oružjem, konjima, životinjama, zbog obveze davanja hrane i pića, kao i zbog plaćanja nadnice (Quod de armis, equis et aliis animalibus et operibus fiat ius omni die.) (Zjačić 1964-1965: 128 i 191).

Nema nikakve sumnje da se ova praksa provodila i u drugim komunama.

\section{Krčme i dućani}

Prema odredbama istarskih statuta krčme se nedjeljom i blagdanom nisu smjele otvarati prije završetka nedjeljne mise.

Prema odredbi 21. glave druge knjige pulskog Statuta, radnje se u Puli nedjeljom i na glavne blagdane te na Božić i Uskrs i u prvi i drugi dan nakon ovih dvaju blagdana nisu smjele otvarati do Terce (De stationibus non aperiendis diebus dominicis et festivis infrascriptis usque ad horam tertiarum), t. j. do devet sati ujutro. (Križman, 2000: 114) Popis blagdana nalazi se na str. $115 / 116$.

Nepoštivanje nedjeljnog odmora kažnjava se npr. u Novigradu s 20 solada, a u Vodnjanu $s$ dvije lire malih denara.

Primjer Vodnjana:

Che non si possa vender vino avanti messa la festa Capitolo XXXVII

Ordinemo che niun osto, overo tavernier di Dignano, abbi ardimento tenir la sua osteria aperta, ne persone che bevessero in quella, nelli giorni di festa contenuti nel Statuto, avanti che sarà stata detta la messa grande, sotto pena di soldi vinti de picoli, dè quali la metà venga nell'accusator et cadauno possi accusar (Lonza et al. 2010: 496).

Na blagdane se ne smije prodavati vino prije mise Glava XXXVII.

Određujemo neka se nijedan vodnjanski gostioničar, odnosno krčmar ne drzne držati otvorenom gostionicu ni imati u njoj ljude koji piju na blagdanske dane navedene u Statutu prije nego što se odsluži svečana misa, pod prijetnjom globe od 20 solada malih denara, od kojih neka polovica pripadne dojavniku i svatko smije dojaviti (Lonza et al. 2010: 497).

Dvigradski statut u glavi 159. predviđa globu od 20 solada za one koji prodaju vino prije mise (Jelinčić et al. 2007: 284/286 i 285/287).

\section{Zaključak}

Čitajući površno istarske statute može nam se učiniti da su, posebno neki od njih, međusobno slični kao jaje jajetu. Ova analiza upućuje na nešto drugačije zaključke.

I još nešto: odredbe su bile vrlo stroge. Nažalost, osim u iznimnim slučajevima, nisu nam se sačuvali kazneni spisi vođeni po ovim statutima pa ne možemo reći koliko su ove norme bile primjenjivane. Treba reći da, proučavajući matične knjige umrlih, rijetko nailazimo na smrtne kazne. Ipak, proučavajući detaljno, nažalost rijetko sačuvano, gradivo sudskih kaznenih procesa iz mletačkog razdoblja (npr. iz Labina i Novigrada) možemo zaključiti da je 
na temelju statutâ izrečen i izvršen ne prevelik broj smrtnih presuda, da je bilo dosta presuda na izgon s određenog područja na duže ili kraće vrijeme te posebno presuda veslanja na galije, dok su globe bile vrlo česte.

\section{POPIS LITERATURE}

\section{JELINČIĆ 1973}

Jakov Jelinčić, „Statut Svetog Lovreča Pazenatičkog sa posebnim osvrtom na jezične karakteristike", Vjesnik Historijskog arhiva u Rijeci $i$ Pazinu, 18, Rijeka 1973., 71-151.

\section{JELINČIĆ - LONZA 2007}

Jakov Jelinčić - Nella Lonza, Statuta communis Duorum Castrorum / Statut Dvigradske općine, početak 15. stoljeća, Kolana od Statuti knjiga I., Pazin - Kanfanar 2007., 6-358.

\section{KLEN 1963-1964}

Danilo Klen, „Statut Grožnjana“, Vjesnik Historijskog arhiva u Rijeci, 10, Rijeka 1963.-1964., 201-243.

\section{KRIŽMAN 2000}

Mate Križman, Statuta Communis Polae / Statut Općine pulske, Pula 2000., 7-301 (i 120 listova preslika).

\section{MAREVIĆ 2000}

Jozo Marević, „Lexicon latino-croaticum encyclopaedicum / Latinsko-hrvatski enciklopedijski rječnik“ I. svezak, A-L; II. svezak M-Z. Marka, Velika Gorica - Matica hrvatska, Zagreb, 2000.

\section{LONZA - JELINČIĆ 2010}

Nella Lonza et al, Vodnjanski statut / Statuto di Dignano MCDXCII, Grad Vodnjan - Državni arhiv u Pazinu, 2010., 8-574.

\section{MORTEANI 1895}

Luigi Morteani, Storia di Montona con appendice e documenti, dio: Statuti e documenti, Trieste 1895., 3-403 (Statut 247-400).

\section{ZJAČIĆ 1963-1964}

Mirko Zjačić, "Statut buzetske općine“, Vjesnik Historijskog arhiva u Rijeci, 8-9, Rijeka 1963.1964., 71-137.

\section{SAŽETAK}

Statuti su kodificirani propisi običajnog prava. Istarsko područje vrlo je bogato sačuvanim statutima, bilo da su sačuvani izvornici (rjeđe) ili prijepisi stariji ili noviji. Većina se ovih statuta čuva u Državnom arhivu u Pazinu (DAPA).

Jedna od glavnih odrednica u statutima istarskih gradova i općina svakako je odnos pojedinca prema Bogu, vjeri i vjerskoj praksi. Gotovo svi oni tretiraju pitanje psovke te rada nedjeljom i zapovijedanim blagdanima. Neki kaznene propise u svezi s psovkom donose na početku, neki u kasnijim odredbama, ali su u svakom slučaju kazne vrlo stroge, a ponekad $i$ drastične (od odsijecanja ili bušenja jezika i drugih fizičkih kazni, do višegodišnjeg izgona iz grada/općine i pripadajućeg teritorija pa i smrti). Vrlo su stroge odredbe o radu nedjeljom i zapovijedanim blagdanom, kao i radom krčmi nedjeljom i blagdanom prije završetka župne mise. Autor na početku rada donosi popis sačuvanih statuta nastalih na području Istre, najprije na području hrvatskog dijela za koji je nadležan Državni arhiv u Pazinu, a zatim i na današnji slovenski i talijanski dio. Dio se statuta čuva u Državnom arhivu u Rijeci (DARI), 
dio u Venciji a dio u Trstu. S obzirom na širinu teme, autor se ograničio na neke od odredbi pojedinih statuta.

Nakon kratkog uvoda autor najprije govori o odredbama koje se tiču psovke te neke od njih navodi u izvorniku i u prijevodu. Slijede odredbe o poštivanju nedjeljnog i blagdanskog odmora. Na kraju posebno navodi neke propise o radu krčmi i dućana nedjeljom i blagdanom.

U kratkom zaključku autor navodi sljedeće: premda se mnogi propisi u ponekim istarskim statutima čine sličnima kao jaje jajetu, ipak se već na temelju analize u ovom radu dolazi do nešto drugačijih zaključaka. Navodi također da se na temelju sačuvanih matičnih knjiga umrlih može ustanoviti da su smrtne kazne rijetko dosuđivane i izvršavane, dok se na temelju proučavanja sačuvanog gradiva nekih komuna (Labina i Novigrada) može također zaključiti da su smrtne presude bile rijetke, ali su presude o izgonu na duže ili kraće vrijeme i slanju na galiju bile dosta česte. Vrlo su česte bile i globe.

\section{SUMMARY}

\section{The Regulations of the Istrian Statutes Regarding the Obedience of the God's and Church's Commands}

The statutes are the coded regulations of the traditional law. The area of Istria is full of richly preserved statutes, whether in original form (which is rare) or in form of older or newer transcriptions. Most of these statutes is preserved in the State Archives in Pazin (DAPA).

One of the main regulations in the statutes of Istrian towns and municipalities is the relation of an individual toward the God, religion and religious practice. Almost all of these regulations treat the issue of swearing, working on Sundays and commanded holidays. Some of penal regulations regarding the swearing are written in the initial part of the regulations, some in later parts, but in all cases they are very severe, sometimes even drastical (from cutting or piercing of the tongue and other physical punishment to several years of expatriation from the town/municipality and its territory, and even death). There are very severe regulations related to the work on Sundays and commanded holidays, as well as the work of taverns on Sundays and holidays before the end of the parish mass. At the beginning of the paper, the author provides the list of the preserved statutes written in the Istra region, first in the area of Croatian part for which the State Archives in Pazin is responsible, and then for today's Slovenian and Italian part. The part of the statues is preserved in the State Archives in Rijeka (DARI), part in Venice and part in Trieste. Regarding the width of the topic, the author limited his attention to some of the regulations of certain statutes.

After the short introduction, the author writes firstly about the regulations related to swearing and mentions some of them in the original text and in the translation. These are followed by the regulations about the Sunday and holiday rest. Finally, the author lists some regulations about the work of taverns and shops on Sundays and holidays.

In the short summary, the author states the following: although many regulations in some Istrian statutes look identical to each other, this analysis provides us with somewhat different conclusions. It is also stated that, on the base of preserved register books of deceased, it can be concluded that the death penalty was very rarely adjudicated and implemented; similarly, based upon the study of the preserved material from some communities (Labin and Novigrad) it can be concluded that the death penalties were rare, 
but the adjudications of expatriations for shorter or longer periods, as well as those of work on galleys, were rather frequent. Also, the penalty fines were also frequently adjudicated.

Keywords: statute, swearing, Sundays and holidays, penalties, penalty fines, expatriation, galley 